\title{
Copper Oxide Nanoparticles for Advanced Refrigerant Thermophysical Properties: Mathematical Modeling
}

\author{
S. A. Fadhilah, ${ }^{1}$ R. S. Marhamah, ${ }^{2}$ and A. H. M. Izzat ${ }^{1}$ \\ ${ }^{1}$ Centre of Advanced Research on Energy, Faculty of Mechanical Engineering, Universiti Teknikal Malaysia Melaka, \\ Hang Tuah Jaya, 76100 Durian Tunggal, Malacca, Malaysia \\ ${ }^{2}$ Faculty of Engineering, Universiti Selangor, Bestari Jaya Campus, Jalan Timur Tambahan, 45600 Bestari Jaya, Selangor, Malaysia
}

Correspondence should be addressed to S. A. Fadhilah; fadhilah@utem.edu.my

Received 16 January 2014; Accepted 13 April 2014; Published 30 April 2014

Academic Editor: Vijaya Rangari

Copyright (C) 2014 S. A. Fadhilah et al. This is an open access article distributed under the Creative Commons Attribution License, which permits unrestricted use, distribution, and reproduction in any medium, provided the original work is properly cited.

\begin{abstract}
In modern days, refrigeration systems are important for industrial and domestic applications. The systems consume more electricity as compared to other appliances. The refrigeration systems have been investigated thoroughly in many ways to reduce the energy consumption. Hence, nanorefrigerant which is one kind of nanofluids has been introduced as a superior properties refrigerant that increased the heat transfer rate in the refrigeration system. Many types of materials could be used as the nanoparticles to be suspended into the conventional refrigerants. In this study, the effect of the suspended copper oxide (CuO) nanoparticles into the 1,1,1,2-tetrafluoroethane, R-134a is investigated by using mathematical modeling. The investigation includes the thermal conductivity, dynamic viscosity, and heat transfer rate of the nanorefrigerant in a tube of evaporator. The results show enhanced thermophysical properties of nanorefrigerant compared to the conventional refrigerant. These advanced thermophysical properties increased the heat transfer rate in the tube. The nanorefrigerant could be a potential working fluid to be used in the refrigeration system to increase the heat transfer characteristics and save the energy usage.
\end{abstract}

\section{Introduction}

A new emerging heat transfer fluid called nanofluid has been introduced in many applications nowadays such as electronic, nuclear reactor, biomedical, automotive, and industrial cooling. In recent years, refrigerant-based nanofluids and nanorefrigerants have been introduced as significant effects of nanoparticles in heat transfer performance and energy consumption reduction [1-3]. Past researches of nanofluids have shown that low concentration of nanoparticles has a promising potential to enhance the thermophysical properties of the base fluids. Since then, the investigations of nanoparticles suspension in the conventional refrigerant have been conducted tremendously. A study proved that the nanoparticles suspension in domestic refrigerators in Malaysia could reduce the energy consumption about 10,863 MWh by the year 2030 [4].

Many studies have been conducted to investigate the thermal conductivity of the nanofluids. However, there are limited literatures on the nanorefrigerants thermal conductivity
[5]. However, researchers agreed that the nanoparticles concentration and types of nanoparticles increased the thermal conductivity of the nanorefrigerant $[1,6]$. A long term stability of nanoparticles dispersion affects the thermal conductivity of the nanorefrigerant since better dispersion behavior showed higher thermal conductivity of nanorefrigerant [7]. By using mathematical modeling methods, it also showed significant influences of $\mathrm{Al}_{2} \mathrm{O}_{3}$ nanoparticle volume fraction on the heat transfer and pressure drop of R14lb refrigerants under constant mass flux, temperature, and pressure [8]. It is important to note that the suspension of $\mathrm{Al}_{2} \mathrm{O}_{3}$ nanoparticles in R-134 refrigerant has reduced the energy consumption about $10.32 \%$ with only $0.2 \%$ of nanoparticles suspension [2]. Under the same tests, 0.1 and $0.5 \mathrm{~g} / \mathrm{L}$ concentrations of $\mathrm{TiO}_{2}$ R600a reduced $5.94 \%$ and $9.60 \%$ energy consumption in domestic refrigerator, respectively [3]. The refrigeration system with mineral oil and $\mathrm{Al}_{2} \mathrm{O}_{3}$ nanoparticles reduced power consumption about $25 \%$ compared the conventional oil [9]. Meanwhile, $\mathrm{Al}_{2} \mathrm{O}_{3} / \mathrm{R} 600$ a nanolubricant reduced power consumption of the compressor about $11.5 \%$ compared to the 
TABle 1: Physical properties of $\mathrm{CuO}$ nanoparticle.

\begin{tabular}{lcccc}
\hline $\begin{array}{l}\text { Nanoparticles } \\
\text { and Conventional conductivity } \\
\text { refrigerant }\end{array}$ & $\begin{array}{c}\text { Thermal } \\
(\mathrm{W} / \mathrm{m} \cdot \mathrm{K})\end{array}$ & $\begin{array}{c}\text { Density } \\
\left(\mathrm{kg} / \mathrm{m}^{3}\right)\end{array}$ & $\begin{array}{c}\text { Diameter } \\
(\mathrm{nm})\end{array}$ & $\begin{array}{c}\text { Viscosity } \\
(\mathrm{Pa} \cdot \mathrm{s})\end{array}$ \\
\hline $\begin{array}{l}\text { CuO (Copper } \\
\begin{array}{l}\text { Oxide) } \\
\text { R-134a }\end{array}\end{array}$ & 32.9 & 6320 & 40 & - \\
\hline
\end{tabular}

conventional POE oil and the coefficient of performance of the refrigeration system enhanced about $19.6 \%$ because of the nanolubricant [10]. There are many factors that influence the thermal conductivity of the nanorefrigerant such as particle volume fraction, nanoparticle types, refrigerants, particle sizes, and particle shapes [1]. The $\mathrm{Al}_{2} \mathrm{O}_{3}$ nanorefrigerant thermal conductivity can be enhanced by increasing the volume fraction of nanoparticles suspended into the R-134a refrigerant [1]. The thermal conductivity of $\mathrm{Al}_{2} \mathrm{O}_{3} / \mathrm{R} 141 \mathrm{~b}$ nanorefrigerant increased with $0.5-2$ vol.\% concentrations and temperature range of $5-20^{\circ} \mathrm{C}$, meanwhile the viscosity of the nanorefrigerant increased with the nanoparticle concentration but decreased with temperature [5].

The viscosity of nanorefrigerant with different type of refrigerant, R-134a also could be enhanced with nanoparticle concentration of 1 to 5 vol.\% theoretically [1]. The study also proved that concentration of the $\mathrm{Al}_{2} \mathrm{O}_{3}$ nanoparticles influenced the pressure drop, pumping power, and heat transfer coefficient of the nanorefrigerant in a horizontal smooth tube. Heat transfer coefficient influenced the heat transfer rate in the cooling system. The enhancement of the heattransfer coefficient due to $\mathrm{Al}_{2} \mathrm{O}_{3}$ nanoparticle concentration is obtained for single-phase laminar flow in microchannel, although there are surface deposition, nanoparticles clustering, and agglomeration in the two-phase regime [11]. This study aims to investigate the thermal conductivity and viscosity of the $\mathrm{CuO} / \mathrm{R}-134 \mathrm{a}$ nanorefrigerant and the heat transfer rate in an evaporator tube is determined by using the thermophysical properties of the nanorefrigerant.

\section{Material Thermophysical Properties and Mathematical Modeling}

2.1. Nanorefrigerant and Tube Design. In this study, the thermophysical properties of nanorefrigerant are investigated by considering the $\mathrm{CuO}$ nanoparticles and the conventional refrigerant, R-134a. Table 1 shows the physical properties of the nanoparticles and refrigerant [12]. A copper horizontal smooth tube of an evaporator is designed by using a CAD software with the inner diameter, $D_{i}$, and length, $L$, being $0.00772 \mathrm{~m}$ and $1.4 \mathrm{~m}$, respectively. Figure 1 shows the copper tube of evaporator. Constant parameters of initial condition in evaporation process have been determined in calculating the properties of nanorefrigerant. Table 2 shows the constant parameters used in this study.

2.2. Mathematical Model of Nanorefrigerant. The thermal conductivity of nanorefrigerant is calculated by using data
TABLE 2: Specification values in determining nanorefrigerant properties.

\begin{tabular}{lc}
\hline Constant parameter & Value \\
\hline Refrigerant velocity, $V$ & $1.2 \mathrm{~m} / \mathrm{s}$ \\
Diameter of nanoparticles, $d_{p}$ & $40 \mathrm{~nm}$ \\
Thermal conductivity of copper, $k_{\text {copper }}$ & $401 \mathrm{~W} / \mathrm{m} \cdot \mathrm{K}$ \\
Heat transfer coefficient for air, $h_{\text {air }}$ & $50 / \mathrm{m}^{2} \cdot \mathrm{K}$ \\
Temperature inlet, $T_{i}$ & $26^{\circ} \mathrm{C}$ \\
Temperature outlet, $T_{o}$ & $-10^{\circ} \mathrm{C}$ \\
\hline
\end{tabular}

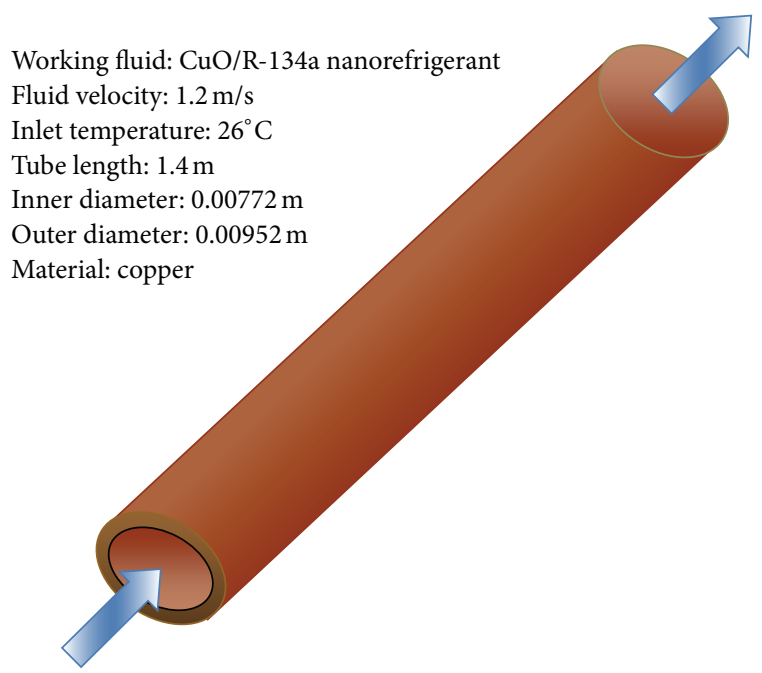

Figure 1: A tube of evaporator with $\mathrm{CuO} / \mathrm{R}-134 \mathrm{a}$ nanorefrigerant.

from Table 2 and mathematical modeling from Vasu et al., [13] as follows:

$$
\frac{k_{\mathrm{nf}}}{k_{m}}=c \operatorname{Re}_{m}^{0.175} \phi_{p}^{0.05}\left(\frac{k_{p}}{k_{m}}\right)^{0.2324}
$$

where $k_{\mathrm{nf}}$ is the thermal conductivity of nanofluid, $k_{m}$ is the thermal conductivity of refrigerant, $k_{p}$ is the thermal conductivity of nanoparticles, $c$ is constant in the equation $(1.298), \phi_{p}$ is the particle volume fraction, $v_{m}$ is the velocity of the refrigerant, $\rho_{p}$ is the density of nanoparticles, $d_{p}$ is the diameter of nanoparticles, and $T_{\text {in }}$ is the temperature inlet. The Reynolds number of nanorefrigerant is calculated by using (2) as follows:

$$
\operatorname{Re}_{m}=\left(\frac{1}{v_{m}}\right)\left(\frac{18 k_{p} T_{\text {in }}}{\pi \rho_{p} d_{p}}\right)^{1 / 2} .
$$

Mahbubul et al. (2013) introduced the Brinkman formula to determine the viscosity of nanorefrigerant, as in (3) which has been used to determine the nanofluids' viscosity:

$$
\mu_{r, n, L}=\mu_{r, L} \frac{1}{(1-\phi)^{2.5}}
$$

where $\mu_{r, n, L}$ is the viscosity of liquid nanorefrigerant, $\mu_{r, L}$ is the viscosity of liquid pure refrigerant, and $\phi$ is the 


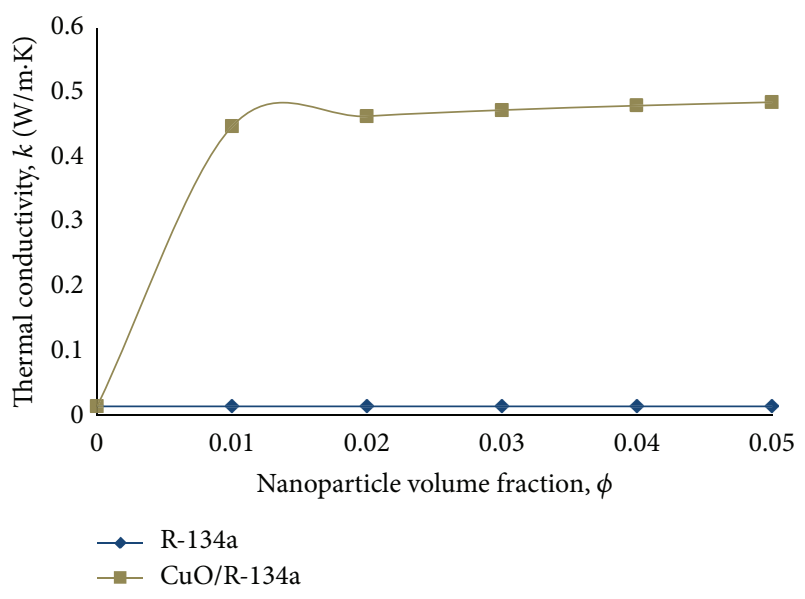

Figure 2: Thermal conductivity as a function of nanoparticle volume fraction.

particle volume fraction of nanoparticles. The viscosity of nanorefrigerant has been influenced by the viscosity of the conventional refrigerant. A general equation of conduction is used in determining the heat transfer rate of flowing nanorefrigerant, meanwhile the heat transfer rate equation is stated in

$$
q=U_{\mathrm{nf}} A(\Delta T),
$$

where $q$ is the heat transfer rate, $U_{\mathrm{nf}}$ is the heat transfer coefficient for nanorefrigerant, $A$ is the area of the tube, and $\Delta T$ is the temperature different between inlet and outlet of the tube. The temperature of the nanorefrigerant in the tube is considered at $26^{\circ} \mathrm{C}$ with the velocity of $1.2 \mathrm{~m} / \mathrm{s}$.

\section{Results and Discussion}

Figure 2 and Table 3 show the relationship between the thermal conductivity of the nanorefrigerant, refrigerant R$134 \mathrm{a}$, and nanoparticle volume fraction. The thermal conductivity of nanorefrigerant, $k_{\mathrm{nf}}$, is directly proportional to the nanoparticle volume fraction. The thermal conductivity of the conventional refrigerant, $0.0139 \mathrm{~W} / \mathrm{m} \cdot \mathrm{K}$, is increased with nanoparticle volume fraction with the increment being about $0.01 \mathrm{~W} / \mathrm{m} \cdot \mathrm{K}$ for each $1 \% \mathrm{CuO}$ nanoparticle concentration addition.

The nanoparticle is suspended into the conventional refrigerant with $1 \%$ volume fraction which causes an increase in the thermal conductivity about $3121 \%$ enhancement from $0.0139 \mathrm{~W} / \mathrm{m} \cdot \mathrm{K}$ to $0.4477 \mathrm{~W} / \mathrm{m} \cdot \mathrm{K}$. The significant enhancement occurred due to interfacial layer consideration in the mathematical modeling. It created equivalent particles with no overlapping between particles. The use of nanoparticle volume fraction up to $5 \%$ increased the thermal conductivity of nanorefrigerant more than $100 \%$ as the conventional refrigerant, R-134a, itself has higher thermal conductivity compared to other types of base fluid such as water and ethylene glycol.

Basically, with more addition of nanoparticles concentration into the nanorefrigerant, the thermal conductivity of

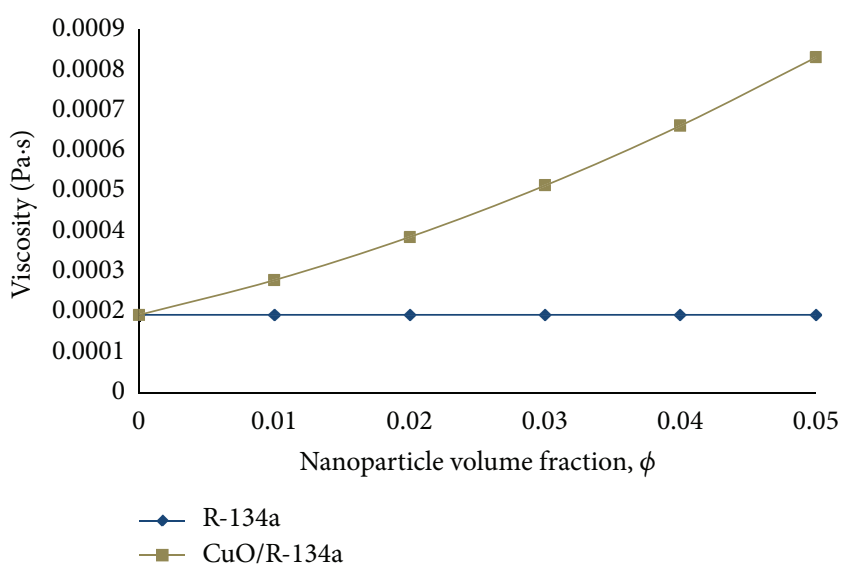

Figure 3: Viscosity as a function of nanoparticle volume fraction.

the nanorefrigerant will be increased accordingly. However, the viscosity of the nanorefrigerant must also be considered since it may affect the overall performance of refrigeration system. The increments of nanorefrigerant viscosity due to nanoparticle suspension are shown in Figure 3. The viscosity is directly proportional to the $\mathrm{CuO}$ nanoparticle volume fraction. The viscosity of $\mathrm{R}-134 \mathrm{a}$ at $26^{\circ} \mathrm{C}$ is $0.0001934 \mathrm{~Pa}$.s. After suspending the nanoparticles into the refrigerant at $1 \%$ nanoparticle volume fraction, the viscosity increased to 0.00027934 Pa.s, about $44.45 \%$ of enhancement as shown in Table 3. A higher increment of the nanorefrigerant viscosity is obtained by suspending additional $1 \%$ of nanoparticle volume fraction. The suspended $\mathrm{CuO}$ nanoparticles have increased the surface area that offered more contact between the R-134a refrigerant and the nanoparticles. The thermal conductivity of nanorefrigerant increases with the increment of surface areas. Thus, calculating heat transfer rate by considering the enhanced thermal conductivity of the nanorefrigerant proved that the heat transfer rate is proportional to the nanoparticle volume fraction as shown in Figure 4 . The heat transfer rate of the R-134a refrigerant increased by $5.1098 \%$ and the increment of the heat transfer rate for $1 \%$ to $5 \%$ volume fraction is about $0.36 \%$ to $1.00 \%$. The Brownian motion of the nanoparticles is the most influential factor to the enhancement of heat transfer rate. The Brownian motion randomly drifted the nanoparticles in the nanorefrigerant that increased the convection processes in the tube. Since copper oxide in nano-size, it allows more movements due to gap between particles and the collisions could be happened continuously.

\section{Conclusion}

The thermal conductivity of refrigerant-134a is $0.0139 \mathrm{~W} / \mathrm{m} \cdot \mathrm{K}$ at temperature of $26^{\circ} \mathrm{C}$. Suspending $1 \%$ vol. fraction of nanoparticles into the refrigerant has increased the thermal conductivity about $3121.05 \%$ enhancements. Additional 1\% vol. fraction has increased the thermal conductivity in range of $3.53-8.38 \%$ up to $5 \% \mathrm{vol}$. fraction. The viscosity of nanorefrigerant is also showing great percentage of enhancement which is about $44.45 \%$ once compared to the conventional 
TABle 3: Nanorefrigerant thermal conductivity enhancement.

\begin{tabular}{lcccc}
\hline $\begin{array}{l}\text { Nanoparticle volume } \\
\text { fraction, } \varnothing(\%)\end{array}$ & $\begin{array}{c}\text { Thermal conductivity } \\
\text { efficiency, }\left(k_{\mathrm{nf}} / k_{\mathrm{bf}}\right)\end{array}$ & $\begin{array}{c}\text { Nanorefrigerant thermal } \\
\text { conductivity enhancement } \\
(\%)\end{array}$ & $\begin{array}{c}\text { Nanorefrigerant viscosity } \\
\text { enhancement }(\%)\end{array}$ & $\begin{array}{c}\text { Heat transfer rate } \\
\text { enhancement }(\%)\end{array}$ \\
\hline 0.01 & 32.21 & 3121 & 44.45 & 5.1098 \\
0.02 & 33.35 & 3234 & 99.58 & 5.4936 \\
0.03 & 34.02 & 3302 & 165.38 & 5.7763 \\
0.04 & 34.52 & 3352 & 241.86 & 6.0011 \\
0.05 & 34.91 & 3390 & 329.025 & 6.1739 \\
\hline
\end{tabular}

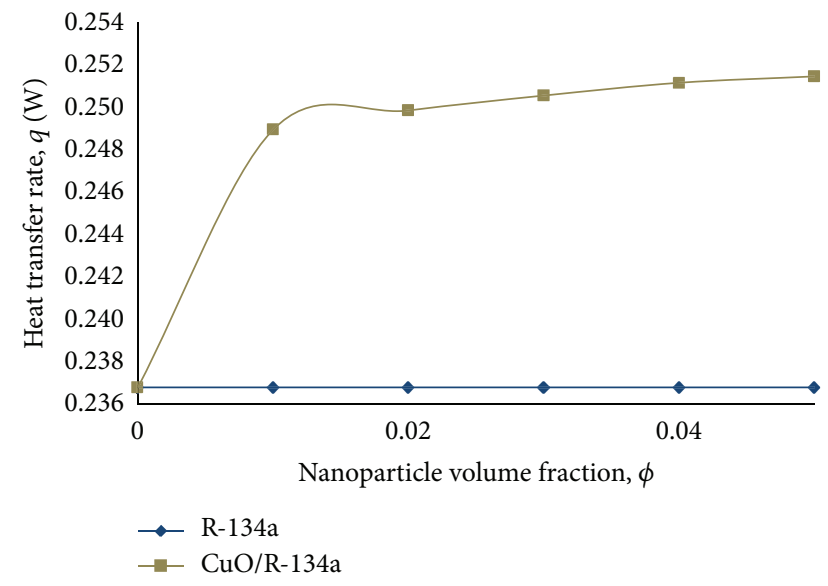

Figure 4: Heat transfer rate as a function of nanoparticle volume fraction.

refrigerant with only $1 \%$ of nanoparticles volume fraction. The heat transfer rate of a tube of nanorefrigerant with 5\% vol. fraction is about $1 \%$ enhancement. This study introduced trends to other researchers to investigate the thermophysical properties of nanorefrigerant experimentally. It is important to have superior thermal properties of the nanorefrigerant that could withstand the variation of temperature and pressures and the nanoparticles would not cause the clogging, corrosion, or pressure drop in the overall performance of refrigeration system.

\section{Conflict of Interests}

The authors declare that there is no conflict of interests regarding the publication of this paper.

\section{Acknowledgment}

Support of this research through a Grant from Universiti Teknikal Malaysia Melaka, Malaysia, for Project no. PJP/2012/FKM(10A)/S0185, is greatly acknowledged.

\section{References}

[1] I. M. Mahbubul, S. A. Fadhilah, R. Saidur, K. Y. Leong, and M. A. Amalina, "Thermophysical properties and heat transfer performance of $\mathrm{Al}_{2} \mathrm{O}_{3} / \mathrm{R}-134 \mathrm{a}$ nanorefrigerants," International
Journal of Heat and Mass Transfer, vol. 57, no. 1, pp. 100-108, 2013.

[2] D. S. Kumar and R. Elansezhian, "Experimental study on $\mathrm{Al}_{2} \mathrm{O}_{3}$ R134a nano refrigerant in refrigeration system," International Journal of Modern Engineering Research, vol. 2, pp. 3927-3929, 2012.

[3] S. Bi, K. Guo, Z. Liu, and J. Wu, "Performance of a domestic refrigerator using $\mathrm{TiO}_{2}$-R600a nano-refrigerant as working fluid," Energy Conversion and Management, vol. 52, no. 1, pp. 733-737, 2011.

[4] F. S. Javadi and R. Saidur, "Energetic, economic and environmental impacts of using nanorefrigerant in domestic refrigerators in Malaysia," Energy Conversion and Management, vol. 73, pp. 335-339, 2013.

[5] I. M. Mahbubul, R. Saidur, and M. A. Amalina, "Influence of particle concentration and temperature on thermal conductivity and viscosity of $\mathrm{Al}_{2} \mathrm{O}_{3} / \mathrm{R} 141 \mathrm{~b}$ nanorefrigerant," International Communications in Heat and Mass Transfer, vol. 43, pp. 100-104, 2013.

[6] R. Saidur, S. N. Kazi, M. S. Hossain, M. M. Rahman, and H. A. Mohammed, "A review on the performance of nanoparticles suspended with refrigerants and lubricating oils in refrigeration systems," Renewable and Sustainable Energy Reviews, vol. 15, no. 1, pp. 310-323, 2011.

[7] G. Ding, H. Peng, W. Jiang, and Y. Gao, "The migration characteristics of nanoparticles in the pool boiling process of nanorefrigerant and nanorefrigerant-oil mixture," International Journal of Refrigeration, vol. 32, no. 1, pp. 114-123, 2009.

[8] I. M. Mahbubul, R. Saidur, and M. a. Amalina, "Heat transfer and pressure drop characteristics of $\mathrm{Al}_{2} \mathrm{O}_{3}$ - $\mathrm{R} 141 \mathrm{~b}$ nanorefrigerant in horizontal smooth circular tube," Procedia Engineering, vol. 56, pp. 323-329, 2013.

[9] N. Subramani and M. J. Prakash, "Experimental studies on a vapour compression system using nanorefrigerants," International Journal of Engineering, Science and Technology, vol. 3, no. 9, pp. 95-102, 2011.

[10] R. R. Kumar, K. Sridhar, and M. Narasimha, "Heat transfer enhancement in domestic refrigerator using R600a/mineral oil/nano- $\mathrm{Al}_{2} \mathrm{O}_{3}$ as working fluid," International Journal of Computational Engineering Research, vol. 3, no. 4, pp. 42-51.

[11] J. Lee and I. Mudawar, "Assessment of the effectiveness of nanofluids for single-phase and two-phase heat transfer in microchannels," International Journal of Heat and Mass Transfer, vol. 50, no. 3-4, pp. 452-463, 2007.

[12] H. Peng, G. Ding, W. Jiang, H. Hu, and Y. Gao, "Heat transfer characteristics of refrigerant-based nanofluid flow boiling 
inside a horizontal smooth tube," International Journal of Refrigeration, vol. 32, no. 6, pp. 1259-1270, 2009.

[13] V. Vasu, K. R. Krishna, and A. C. S. Kumar, "Empirical correlations to predict thermophysical and heat transfer characteristics of nanofluids," Journal of Thermal Science, vol. 12, no. 2, pp. 2737, 2008. 

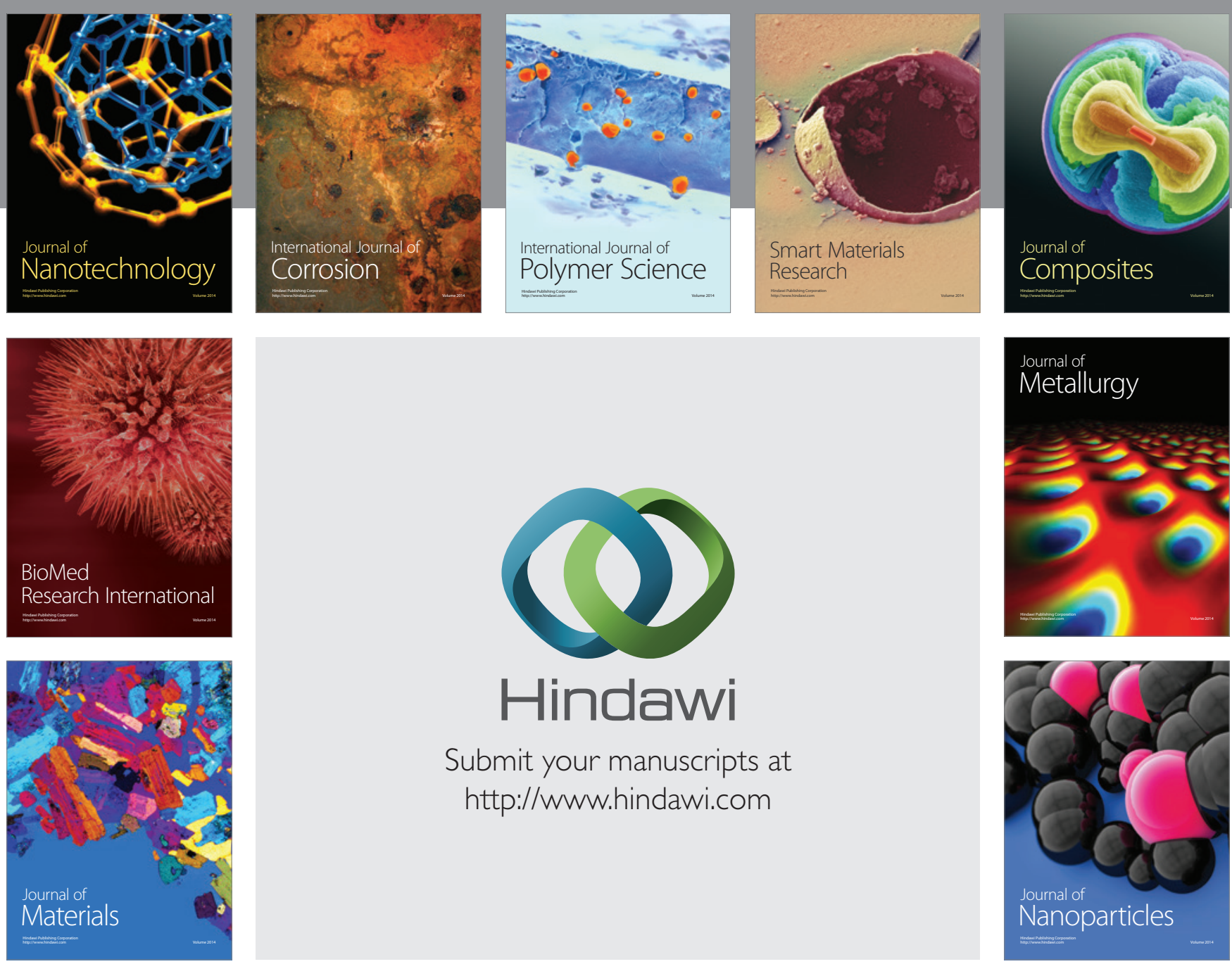

Submit your manuscripts at http://www.hindawi.com
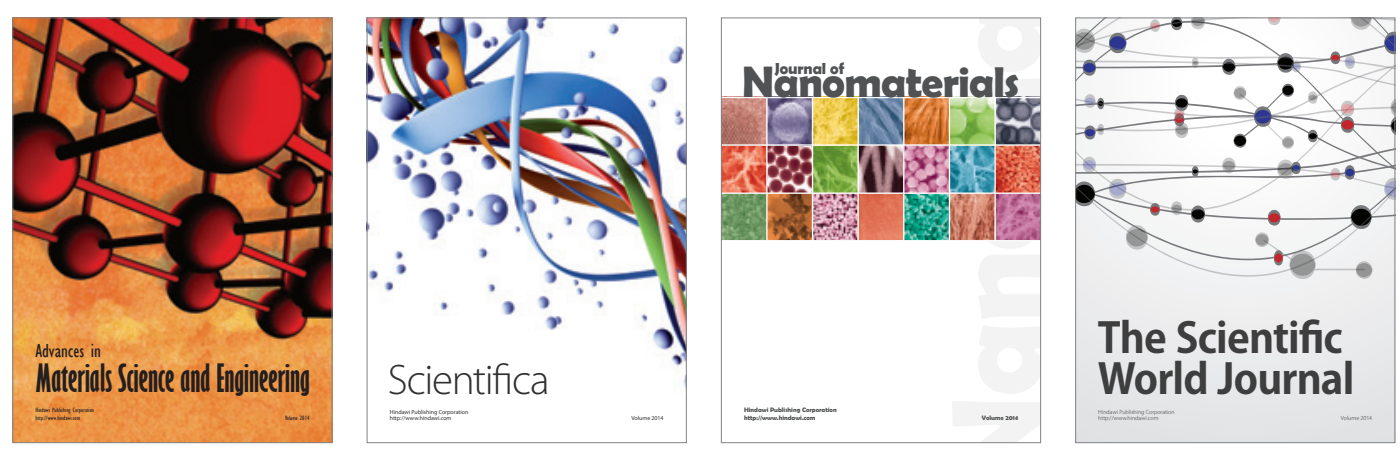

\section{The Scientific World Journal}
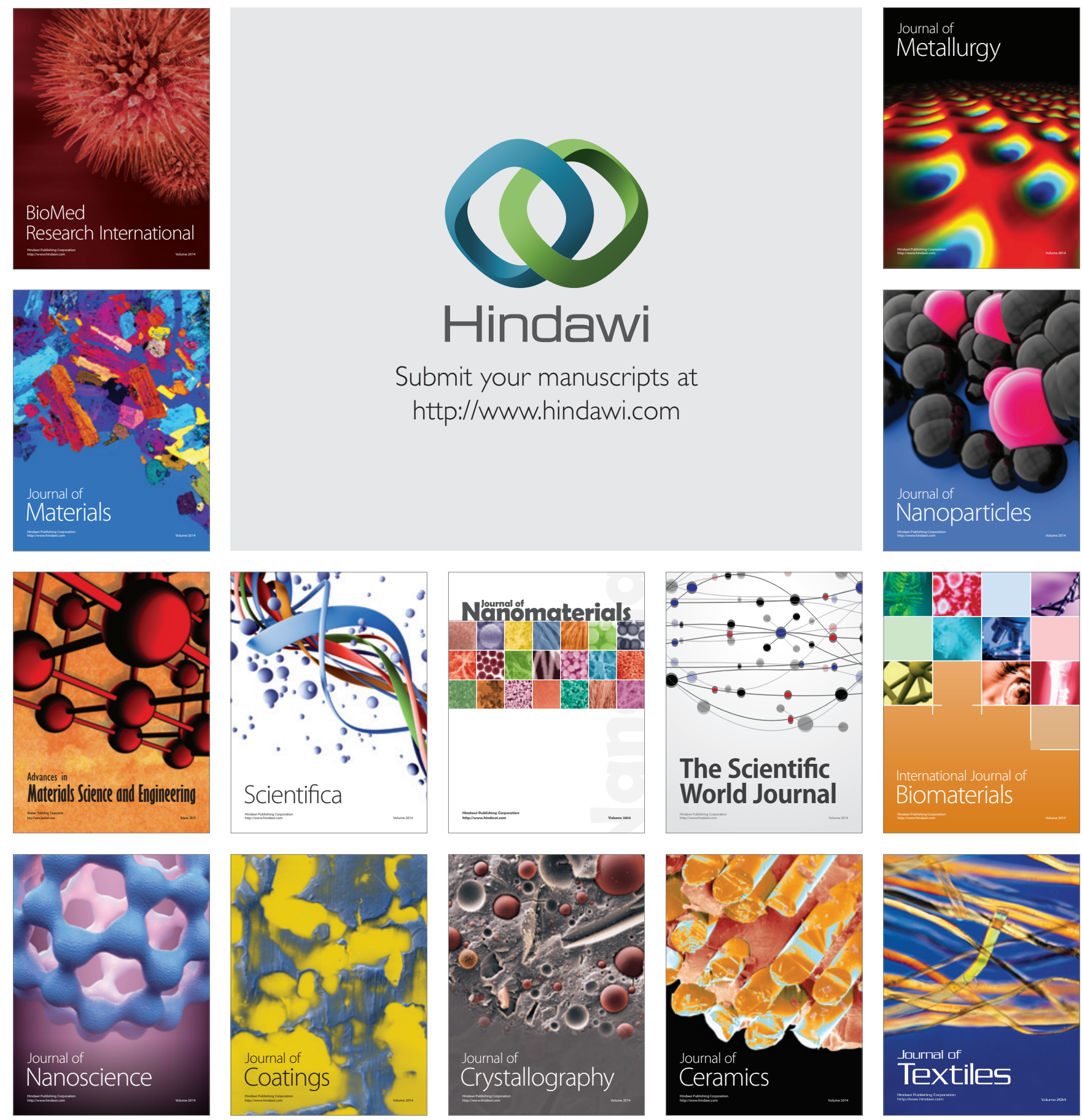